\title{
Rapid growth of a left atrial myxoma shown by echocardiography
}

\author{
RAYMOND ROUDAUT, PHILIPPE GOSSE, MODESTE DALLOCCHIO \\ From the Hopital Cardiologique, Centre Hospitalier et Universitaire de Bordeaux, Pessac, France
}

SUMMARY Rapid growth of a left atrial myxoma was demonstrated in a patient who showed no echocardiographic evidence of the tumour when he was admitted for coronary artery bypass grafting. Eight months later he complained of dyspnoea and fatigue, and cross sectional echocardiography showed a $6 \times 4 \mathrm{~cm}$ left atrial myxoma. This was removed and the diagnosis was confirmed by histological examination.

Although atrial myxomas are rare they are the most common primary cardiac tumour. With the development of cross sectional echocardiography the diagnosis of atrial myxoma at an earlier stage has become easier, and recognised cases are becoming more common. However, few data have been collected about the growth of the tumour. The interval from the onset of symptoms to operation or death varied from two days to eight years (mean 16 months) in the retrospective study of St John Sutton et al. ${ }^{1}$ In the same study there were two recurrences within three years of resection.

We report the clinical, echocardiographic, angiographic, and morphological results in a patient in whom rapid growth of a left atrial myxoma over seven months was demonstrated.

\section{Case report}

A 45 year old man was referred to the Hôpital Cardiologique, Bordeaux, in April 1983 for evaluation of coronary artery disease a few weeks after an inferior myocardial infarction. At this first examination no murmur was heard. A cross sectional echocardiogram showed a normal sized left ventricle with reduced motion of the inferior wall. Mitral valve motion was normal and the left atrium was free of any visible mass (figs 1 and 2). A coronary angiogram showed three vessel disease with complete obstruction of the right coronary artery. Right ventriculography was not performed; there was no

Requests for reprints to Dr Raymond Roudaut, Hôpital Cardiologique, Avenue de Magellan, 33604 Pessac, France. neovascularity of the atrium. The patient subsequently underwent coronary artery bypass surgery. The operation was successful and uncomplicated. A postoperative echocardiogram was normal except for showing evidence of persistent hypokinesia of the inferior wall. Eight months later the patient complained of fatigue and dyspnoea (class III New York Heart Association). Cardiac examination showed a regular rhythm, an accentuated first heart sound, and a diastolic sound. The appearance of the electrocardiogram was unchanged. A cross sectional echocardiogram showed a large globular mass $(6 \times 4 \mathrm{~cm})$ in the left atrium, protruding through the mitral valve during diastole. The tumour was attached to the interatrial septum by a short broad stalk (figs 1 and 2). A pulmonary cineangiogram confirmed the presence of a large left atrial mass which moved through the mitral valve into the left ventricle during diastole. This filling defect was also visible during left ventriculography at the level of the inflow tract. It had not been present on the first left ventriculogram in April. Furthermore, selective angiography of the right coronary artery graft produced a tumour blush through small branches of the distal right coronary artery. A $5.5 \times 4 \mathrm{~cm}$ tumour was removed. It had a smooth external surface and was attached to the interatrial septum. The mass had the typical gross and histoligical features of a myxoma. Light microscopy of haematoxylin and eosin stained sections disclosed typical scale-like myxoma cells. Alcian blue stained sections showed the extensive glycosaminoglycan ground substance that is characteristic of a myxoma matrix. A myxosarcoma was excluded. The patient remains well three years after operation. 


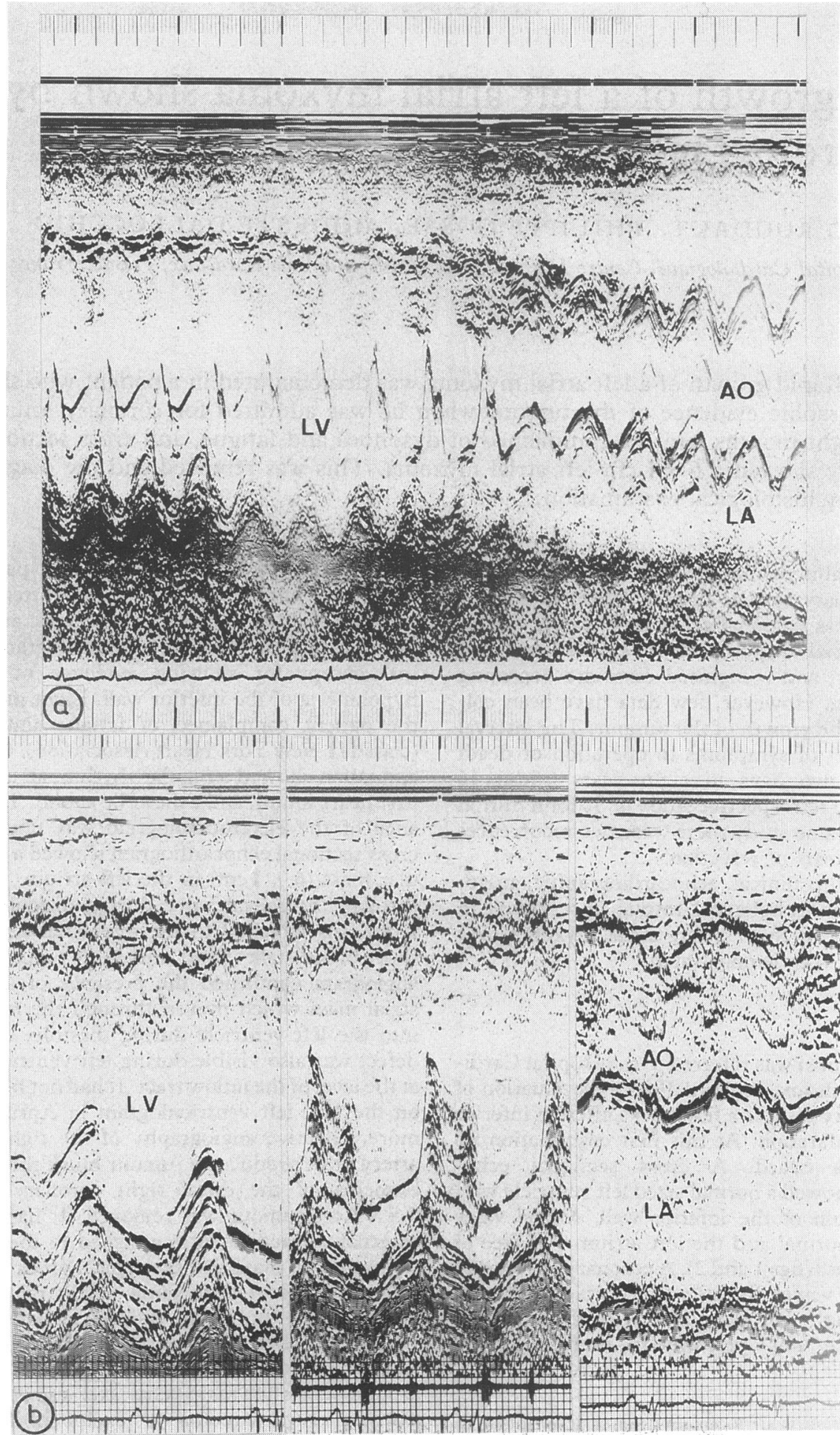

Fig $1 M$ mode echocardiograms. (a) Recorded in April when mitral valve motion was normal and left atrium ( $L A$ ) appeared to be free of any visible mass ( $L V$, left ventricle). (b) Eight months later abnormal echoes showed the presence of a mass protruding through the mitral valve during diastole. 

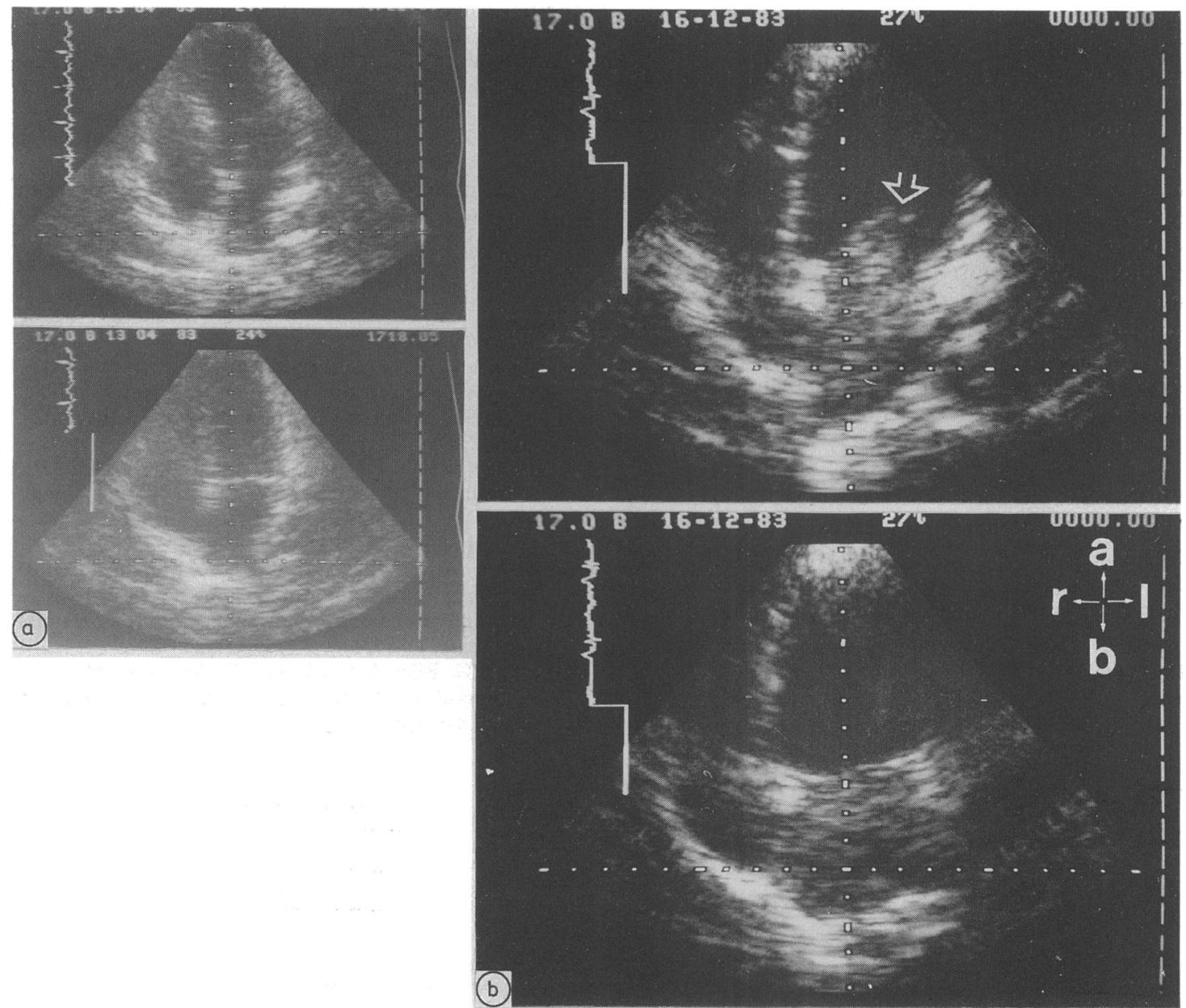

Fig 2 Apical four chamber views. (a) In April when the chamber was free of abnormal masses. (Top, diastole; bottom, systole). Left cavities are on the right. (b) Eight months later a large mass was seen in the left atrium during systole (bottom). During diastole the mass protruded through the mitral valve into the left ventricular inflow tract (top). ( $a, a p e x ; b, b a s e ; r$, right; $l$, left).

\section{Discussion}

The time taken for an atrial myxoma to produce symptoms is variable. ${ }^{2-4}$ To our knowledge this is the first well documented case of rapid growth of an atrial myxoma. Cases of rapid recurrence of left atrial myxoma have been reported, however. St John Sutton et al reported two tumour recurrences within three years of myxoma resection. ${ }^{1}$ Read et al reported two recurrences of the tumour in the same patients $\mathrm{s}^{5}$; the first myxoma was attached to the interatrial septum and was excised and the first recurrence (from the left posterolateral atrial wall) occurred 15 months after resection. Because the base of the second tumour could not be removed completely it was cauterised. Seven months after the second operation there was a second recurrence from the previously cauterised base. Read et al concluded that partial excision was the most likely cause of recurrence but that rapid recurrence does not always follow incomplete resection. ${ }^{6}$

Some workers have described rapid symptomatic deterioration probably caused by haemorrhage within the rapidly enlarging myxoma. ${ }^{7}$ In our experience of 26 atrial myxomas we found only one recurrence; this occurred seven years after the initial resection.

Cross sectional echocardiography should be re- 
peated if new clinical features develop that are compatible with an intracardiac tumour. Multiple views were recorded during each examination in the present case. We believe that the tumour was too small to be seen at the first examination. The tumour in our case was unusually vascular. Increased vascularity is also found in cases of left atrial thrombi. ${ }^{8}$ Some workers believe that highly vascularised myxomas may be difficult to diagnose by echocardiography because their echogenicity is low. ${ }^{9}$ In our case, however, vascularisation of the left atrium was not abnormal on the first coronary angiogram in April and when the tumour was discovered by cross sectional echocardiography the following December the mass showed considerable homogeneous echogenicity.

We thank Professor F Fontan and Dr N Sourdille for their contributions to this study and Professor A de Mascarel and Dr J F Goussot, Service d'Anatomopatholgie, Hôpital St André, 33000 Bordeaux, who performed the histological examination.

\section{References}

1 St John Sutton M, Mercier LA, Giuliani ER. Atrial myxoma: a review of clinical experience in 40 patients. Mayo Clin Proc 1980;55:371-6.

2 Oldershaw PJ, St John Sutton M, Gibson RV. Long asymptomatic period of atrial myxomas. Thorax 1980:35:70-9.

3 Bulkley BH, Hutchins GM. Atrial myxoma: a fifty year review. Am Heart J 1979;97:639-43.

4 Croxson RS, Jewitt D, Bentall HH, Cleland WP, Kristinsson A, Goodwin JF. Long-term follow up of atrial myxoma. Br Heart $J$ 1972;34:1018-23.

5 Read RC, White HJ, Murphy MC, Williams D, Sun $\mathrm{CN}$, Flanagan WH. The malignant potentiality of left atrial myxoma. J Thorac Cardiovasc Surg 1974;68:857-68.

6 Richardson JU, Brandt B, Doty DB, Ehrenhaft JL. Surgical treatment of atrial myxomas: early and late results of 11 operations and review of the literature. Ann Thorac Surg 1979;28:354-8.

7 Pandian NG, Isner JE, McInerney KP, Caldeira ME, Donaldson RF. Left atrial myxoma. Implications of site, size, mobility and tissue structure. Echocardiography 1985;2:113-8.

8 Shapiro MR, Cohen MV, Grose R, Spindola-Franco $H$. Diagnosis of left atrial myxoma by coronary arteriography eight years following open mitral commissurotomy. Am Heart J 1983;15:325-7.

9 Come PC, Riley MF, Markis JE, Malagold M. Limitations of echocardiographic technique in evaluation of left atrial masses. Am J Cardiol 1981;48:947-53. 